\title{
Acute Colchicine Poisoning Causes Endotoxemia via the Destruction of Intestinal Barrier Function: The Curative Effect of Endotoxin Prevention in a Murine Model
}

\author{
Kie Horioka ${ }^{1} \cdot$ Hiroki Tanaka $^{1} \oplus$. Shotaro Isozaki ${ }^{2} \cdot$ Hiroaki Konishi $^{3} \cdot$ Mikihiro Fujiya $^{2,3} \cdot$ Katsuhiro Okuda $^{1}$. \\ Masaru Asari ${ }^{1} \cdot$ Hiroshi Shiono ${ }^{1} \cdot$ Katsuhiro Ogawa $^{4} \cdot$ Keiko Shimizu $^{1}$
}

Received: 28 March 2019 / Accepted: 9 July 2019 / Published online: 17 July 2019

(c) The Author(s) 2019

\begin{abstract}
Background Colchicine binds to intracellular tubulin and prevents mitosis. Colchicine is also used as an anti-inflammatory drug. Meanwhile, excess administration of medication or accidental ingestion of colchicine-containing plants can cause acute colchicine poisoning, which initially results in gastrointestinal effects that may be followed by multiorgan dysfunction. However, the mechanism of colchicine poisoning remains unclear, and there are no standard therapeutic strategies.

Aims We focused on intestinal barrier function and attempted to reveal the underlying mechanism of colchicine poisoning using an animal model.

Methods Colchicine was orally administered to C57B1/6 mice. Then, we performed histopathological analysis, serum endotoxin assays, and intestinal permeability testing. Additionally, the LPS-TLR4 signaling inhibitor TAK-242 was intraperitoneally injected after colchicine administration to analyze the therapeutic effect.

Results We observed villus height reduction and increased numbers of apoptotic cells in the gastrointestinal epithelium of colchicine-treated mice. Both intestinal permeability and serum endotoxin levels were higher in colchicine-treated mice than in control mice. Although colchicine-poisoned mice died within $25 \mathrm{~h}$, those that also received TAK-242 treatment survived for more than $48 \mathrm{~h}$.

Conclusion Colchicine disrupted intestinal barrier function and caused endotoxin shock. Therapeutic inhibition of LPS-TLR4 signaling might be beneficial for treating acute colchicine poisoning.
\end{abstract}

Keywords Colchicine $\cdot$ Intestinal barrier $\cdot$ Endotoxin

Hiroki Tanaka

hiroki-t@asahikawa-med.ac.jp

1 Department of Legal Medicine, Asahikawa Medical University, 2-1-1-1 Midorigaoka-Higashi, Asahikawa, Hokkaido 078-8510, Japan

2 Division of Gastroenterology and Hematology/Oncology, Asahikawa Medical University, Asahikawa, Japan

3 Department of Gastroenterology and Advanced Medical Science, Asahikawa Medical University, Asahikawa, Japan

4 Department of Pathology, Asahikawa Medical University, Asahikawa, Japan

\section{Introduction}

Colchicine is a natural alkaloid present in plants such as $\mathrm{Col}$ chicum autumnale (meadow saffron) and Gloriosa superba (glory lily). Colchicine binds to the intracellular protein tubulin, preventing its alpha and beta forms from polymerizing to form microtubules [1-3]. Colchicine therefore arrests mitosis in metaphase because chromosome separation depends on microtubule function [1-3]. Disruption of the microtubule network also results in low expression of adhesion molecules on neutrophil membranes and reduced motility [1-3]. Thus, colchicine has anti-inflammatory activity, and it is used mainly to treat gout and familial Mediterranean fever. Recently, colchicine has also been used as a second-line treatment for pericarditis [4, 5]. Colchicine is safe when it is administered according to established therapeutic guidelines. However, in some cases, gastrointestinal 
side effects can occur [1-3]. Additionally, at excessive doses, colchicine causes serious systemic toxicity. Acute colchicine poisoning is uncommon, but it is associated with a high mortality rate. It is caused by either the accidental ingestion of colchicine-containing plants or excess administration of colchicine as a drug [6-10]. For instance, Colchicum autumnale closely resembles wild garlic (Allium ursinum) eaten as a wild vegetable. It has thus been mistaken for this plant, resulting in poisoning deaths [6-8]. In previous case reports, acute colchicine poisoning has resulted initially in gastrointestinal effects lasting for approximately $24 \mathrm{~h}$, whereas these initial effects may be followed by multiorgan failure or death from cardiogenic shock, usually occurring within 48-96 h [1]. The physiological cell cycle at the crypts of the intestinal epithelium is important for maintaining intestinal barrier function [11]. Disruption of barrier function causes lipopolysaccharide (LPS) to enter the blood flow [11, 12]. LPS stimulates the secretion of various pro-inflammatory cytokines such as tumor necrosis factor- $\alpha$ (TNF- $\alpha$ ) through Toll-like receptor 4 (TLR4) in immune cells and induces endotoxin shock. Therefore, we hypothesized that the aberrant intestinal barrier function and endotoxemia observed during acute colchicine poisoning are caused by cell cycle arrest in the intestinal mucosa, representing a potentially critical cause of death. However, the detailed mechanisms of colchicine poisoning remain unclear, and no standard therapeutic strategies have been available until recently. In this study, we focused on intestinal barrier function and sought to reveal the molecular mechanism underlying colchicine poisoning using an animal model.

\section{Materials and Methods}

\section{Animal Models}

The experimental procedures were approved by the Animal Experiments Committee of Asahikawa Medical University based on the guidelines for the protection of animals, and all other methods were performed in accordance with the relevant guidelines and regulations. Colchicine $(30 \mathrm{mg} / \mathrm{kg})$ was orally administered to male C57B1/6 mice to create a colchicine-poisoned model. Mice were granted free access to a regular diet and water after colchicine treatment. The animals were euthanized $3,6,9,12$, and $18 \mathrm{~h}$ after treatment. For the therapeutic study in colchicine-poisoned mice, the LPS-TLR4 signaling inhibitor TAK-242 $(5 \mathrm{mg} / \mathrm{kg})$ was intraperitoneally injected $3 \mathrm{~h}$ after colchicine administration. Saline was intraperitoneally injected $3 \mathrm{~h}$ after colchicine administration as a vehicle group. These mice were maintained and monitored under normal conditions to perform Kaplan-Meier survival analysis. Blood and intestinal samples were collected $18 \mathrm{~h}$ after colchicine administration for serum analysis and intestinal permeability testing. For the blood samples, blood was collected from the inferior vena cava. Because a previous report found that colchicine induced apoptosis mainly in the duodenum and jejunum in a murine colchicine-poisoned model [13], we collected the middle of the jejunum $(6 \mathrm{~cm}$ of intestinal tissue: ranging from 4 to $10 \mathrm{~cm}$ downward from the gastric pylorus) as the intestinal tissue.

\section{Histopathological Analysis}

The tissue samples taken from the mice were processed into formalin-fixed paraffin-embedded tissue blocks and subjected to H\&E staining. The average villus height was measured under microscopic observation. The height of 100 villi per mouse was analyzed, and the average was calculated. For this analysis, five mice each were used for the control and colchicine-poisoned groups. For immunohistochemistry, 3.0- $\mu \mathrm{m}$-thick paraffin sections were sequentially treated before the application of primary antibodies through the following process: deparaffinization, rehydration, endogenous peroxidase quenching, and antigen retrieval. The tissue sections were first incubated with cleaved caspase-3 rabbit monoclonal antibody (Cell Signaling Technology, Danvers, MA, USA) or anti-ZO-1 antibody (GeneTex, Irvine, CA, USA). Antibody binding was visualized using ImmPRESS reagent (Vector Labs, Burlingame, CA, USA). Microscopic observation of five fields ( $\times 400$ magnification) per mouse was performed to analyze the frequencies of cleaved caspase-3-positive epithelial cells and ZO-1-absent villi, and the averages were calculated. The analysis was performed using three mice per each time point.

\section{Scanning Electron Microscopy}

The small intestine samples taken from the mice were fixed in $2.5 \%$ glutaraldehyde and cut into small pieces, which were then fixed in $1 \%$ osmium for $1 \mathrm{~h}$. The samples were then processed for sequential alcohol dehydration and infiltrated with $t$-butyl alcohol. After freezing, the tissues were vacuum-dried and then coated using a Hitachi E-1030 ion sputter (Hitachi, Tokyo, Japan) for analysis using an SEM S-4100 scanning electron microscope (Hitachi).

\section{Serum Analysis}

The serum levels of mouse TNF- $\alpha$ were analyzed via enzyme-linked immunosorbent assay (ELISA) using a mouse TNF- $\alpha$ ELISA kit (R\&D Systems, Minneapolis, MN, USA). Serum endotoxin levels were analyzed using the Limulus amebocyte lysate chromogenic endpoint assay (GenScript, Piscataway, NJ, USA). An EnsPire multimode plate reader (PerkinElmer, Waltham, MA, USA) was used for the 
analysis. The colchicine levels in whole blood samples were measured via LC-MS analysis. For $20 \mu \mathrm{L}$ of whole blood samples, $20 \mu \mathrm{L}$ of D5-diazepam $(125 \mathrm{ng} / \mathrm{mL})$ were added as an internal standard, and then the mixture was diluted with $60 \mu \mathrm{L}$ of methanol. Ultrasonic extraction was performed on the solution. The centrifuged supernatants of each extract were filtrated using $0.45-\mu \mathrm{m}$ GHP Nanosep-MF centrifugal devices (Pall Life Sciences, Ann Arbor, MI, USA) prior to LC-MS/MS analysis. LC-MS/MS analysis was conducted using an API 3200 Q TRAP system (Applied Biosystems, Waltham, MA, USA) coupled to a Shimadzu HPLC Prominence system (Shimadzu, Kyoto, Japan), and the electrospray ionization method was used for measurement.

\section{Intestinal Permeability Test}

Small intestines were taken from the mice $18 \mathrm{~h}$ after colchicine administration, each end ligated with silk sutures and filled with medium containing ${ }^{3} \mathrm{H}-\mathrm{D}-\mathrm{mannitol}$. The intestines were incubated in culture medium, and after 5,20, and $35 \mathrm{~min},{ }^{3} \mathrm{H}$ radioactivity leakage from inside the intestines was measured via liquid scintillation counting [14].

\section{Statistics}

The differences in the experimental values between colchicine-poisoned and control mice were statistically analyzed using Student's paired $t$ test, the Chi squared test, two-way ANOVA, and one-way ANOVA followed by the Tukey-Kramer method.

\section{Results}

\section{Morphological Observations in Colchicine-Poisoned Mice}

In the histopathological analysis conducted $18 \mathrm{~h}$ after colchicine administration, the length of villi in the small intestine was shorter in colchicine-poisoned mice than in control mice. Additionally, we observed vasodilation and stromal edema in the submucosal layers in colchicine-poisoned mice without significant inflammatory cell infiltration (Fig. 1a). The average villus height was significantly shorter in colchicine-poisoned mice than in control mice, indicating that colchicine poisoning inhibited epithelial cell turnover (Fig. 1b). When we analyzed colchicine levels in whole blood taken from the mice, colchicine levels of $51.6-265.0 \mathrm{ng} / \mathrm{mL}$ were detected (Fig. 1c). Via scanning electron microscopy, we observed dilated intercellular spaces between epithelial cells on the surface of intestinal villi in colchicine-poisoned mice, whereas dilated intercellular spaces were not observed in control mice (Fig. 1d).

\section{Time Sequence of Changes in the Small Intestine After Colchicine Treatment}

Via immunohistochemical staining for cleaved caspase-3, we observed that the number of apoptotic cells started to increase $12 \mathrm{~h}$ after colchicine administration in the intestinal crypts, whereas positive staining was less frequent at earlier time points (Fig. 2a, c). When we stained the tight junction protein ZO-1 in the mice, we clearly observed ZO-1 expression bordering the edge of villi in control mice as well as mice euthanized 3-12 $\mathrm{h}$ after colchicine administration (Fig. 2b). However, ZO-1 expression was absent at some parts of the villi in mice euthanized $18 \mathrm{~h}$ after colchicine administration (Fig. 2b, d).

\section{Intestinal Permeability in Colchicine-Poisoned Mice}

At 3-12 $\mathrm{h}$ after colchicine administration, serum endotoxin levels were not significantly different from those in control mice. However, serum endotoxin levels increased $18 \mathrm{~h}$ after colchicine administration (Fig. 3a). Similarly, the levels of TNF- $\alpha$ at $18 \mathrm{~h}$ after colchicine administration were significantly higher than those at earlier time points (Fig. 3b). When we evaluated the effect of colchicine on intestinal permeability using ${ }^{3} \mathrm{H}$-D-mannitol, 3-5-fold more ${ }^{3} \mathrm{H}$ radioactivity leaked from the intestine in colchicine-poisoned mice than in control mice $18 \mathrm{~h}$ after colchicine administration, indicating that colchicine treatment disrupted intestinal barrier function (Fig. 3c).

\section{Prevention of Endotoxin Bioactivity Inhibits Death After Colchicine Poisoning}

To analyze whether the inhibition of endotoxin bioactivity has a therapeutic effect against colchicine poisoning, we treated colchicine-poisoned mice with the LPS-TLR4 signaling inhibitor TAK-242 [15]. Although all colchicinepoisoned mice that received saline injection died within $25 \mathrm{~h}$ after colchicine administration, all mice that received TAK-242 treatment survived for more than 48 h (Fig. 4a). Conversely, we did not observe a significant reduction of serum endotoxin levels in TAK-242-treated mice (Fig. 4b). In addition, TAK-242 treatment did not significantly ameliorate intestinal permeability as evaluated using ${ }^{3} \mathrm{H}$ radioactive mannitol leakage (Fig. 4c). However, treatment with TAK-242 significantly inhibited the increases of TNF- $\alpha$ in colchicine-poisoned mice (Fig. 4d).

\section{Discussion}

At toxic doses, colchicine binds to tubulin, interferes with microtubule structure, and inhibits cell division. Organs with the highest cell turnover rates such as the gastrointestinal 

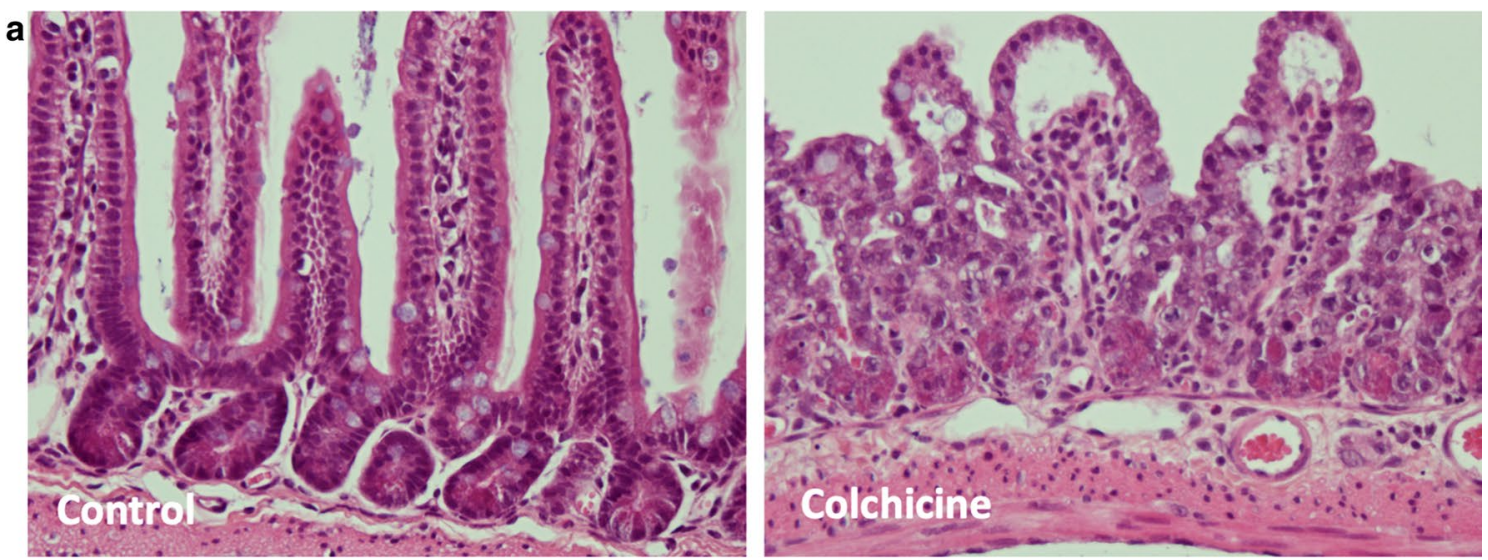

b

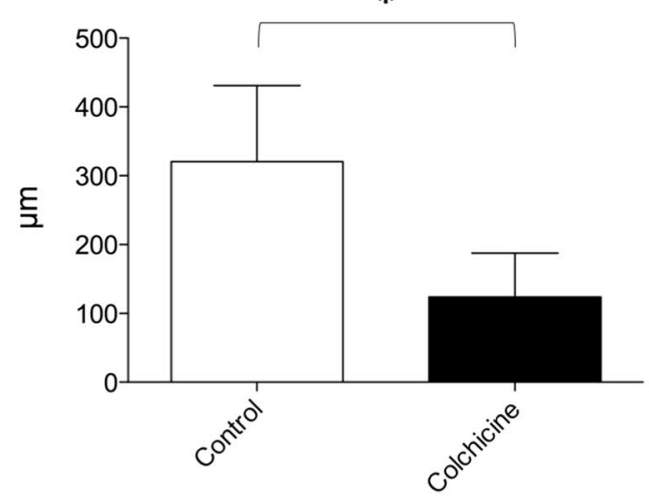

c

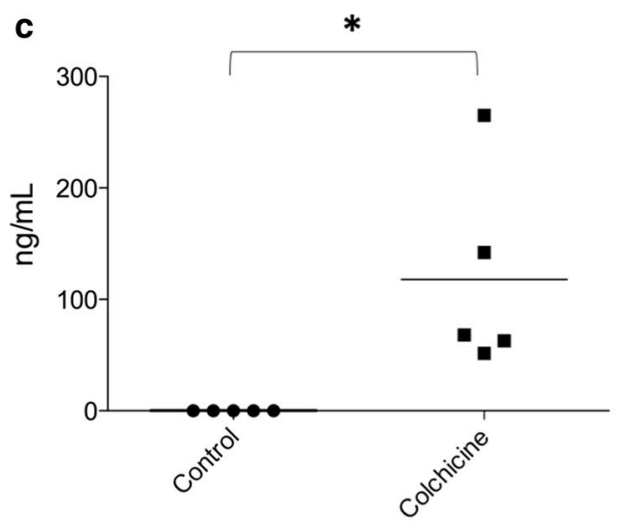

d
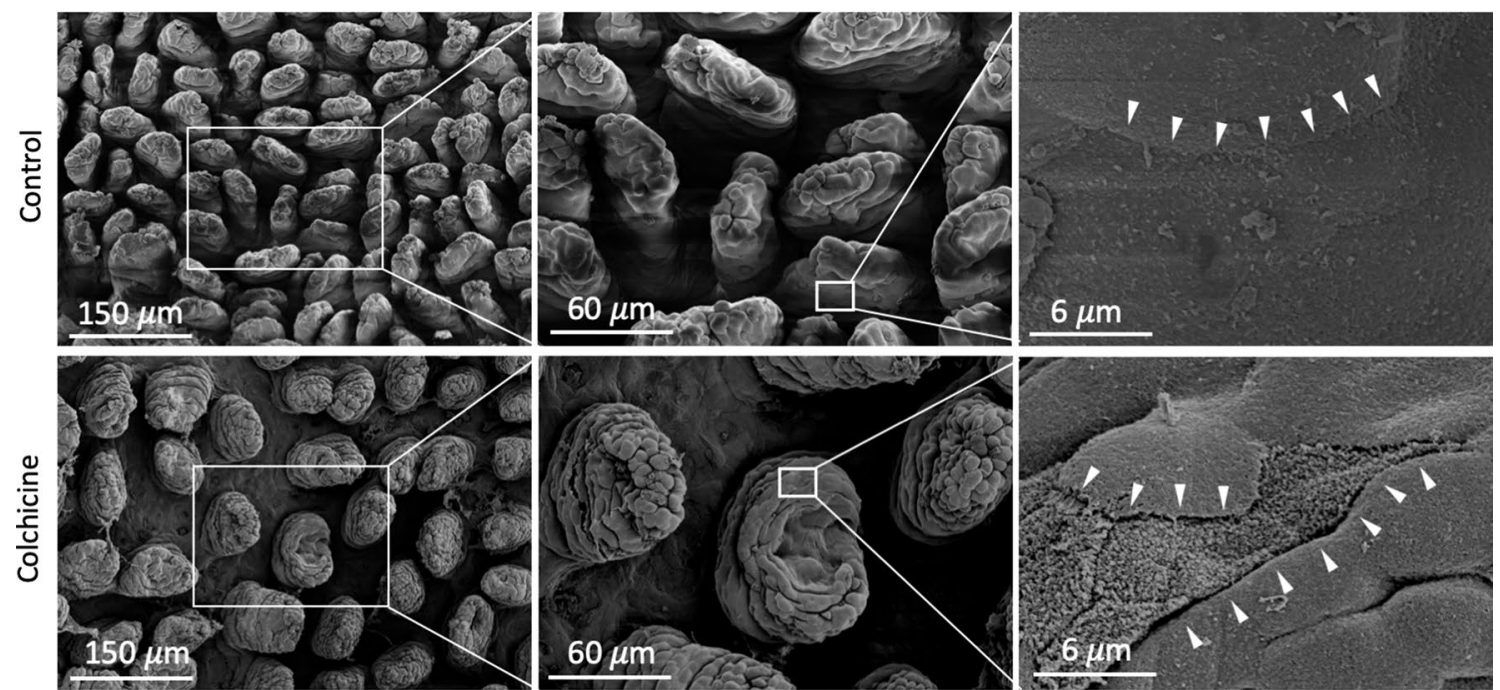

Fig. 1 Morphological observations in colchicine-poisoned mice. a $\mathrm{H} \& \mathrm{E}$ staining in control and colchicine-poisoned mice. $\mathbf{b}$ The average villus length $(n=5, * P<0.05)$. The error bar indicates the SD. $\mathbf{c}$ The contents of colchicine in the whole blood of mice $(n=5, * P<0.05)$.

tract, bone marrow, and hair follicles are the most vulnerable to colchicine. In previous reports, colchicine poisoning resulted in gastrointestinal effects approximately $24 \mathrm{~h}$ after ingestion followed by multiorgan dysfunction or cardiac d Scanning electron microscopy of the surface of intestinal villi. These analyses were performed using samples obtained $18 \mathrm{~h}$ after colchicine administration

arrest, usually within 48-96 h [1]. This time course corresponds with the cell turnover of the gastrointestinal tract, which is known to range $2-6$ days [1]. Consequently, we hypothesized that cell cycle inhibition and cell death in the 
a

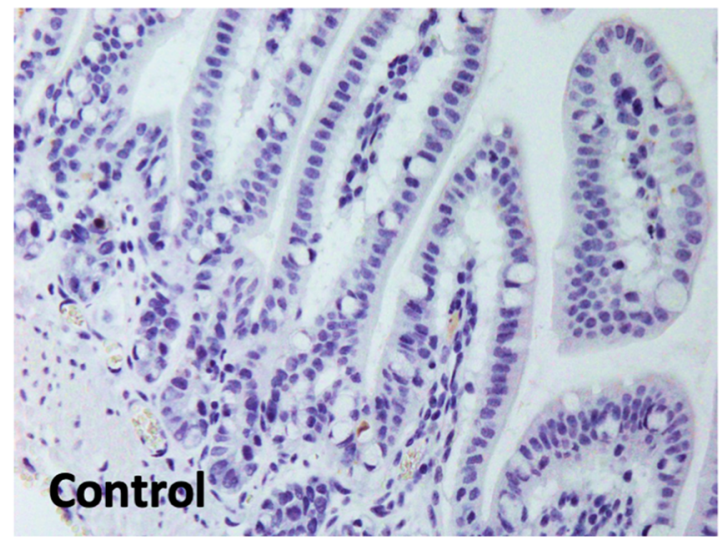

b

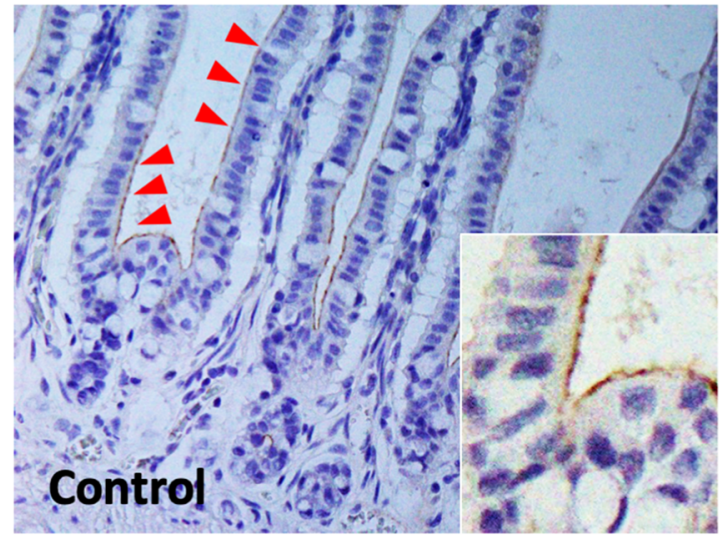

C

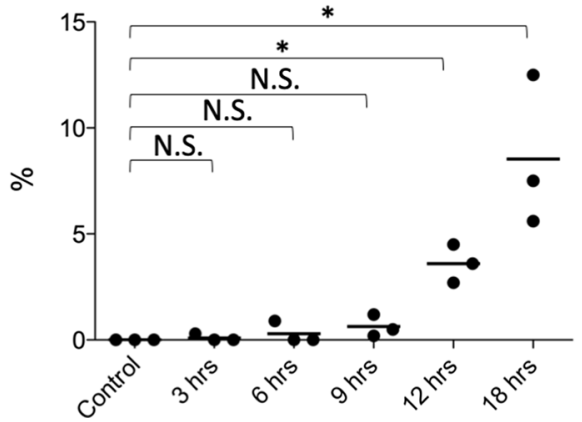

Fig. 2 Immunohistochemical analysis in colchicine-poisoned mice. a Immunohistochemical staining of cleaved caspase-3 as an apoptosis marker (left: control, right: $18 \mathrm{~h}$ after colchicine administration). b Immunohistochemical staining of ZO-1 as a marker of intestinal barrier (left: control, right: $18 \mathrm{~h}$ after colchicine administration). c Time
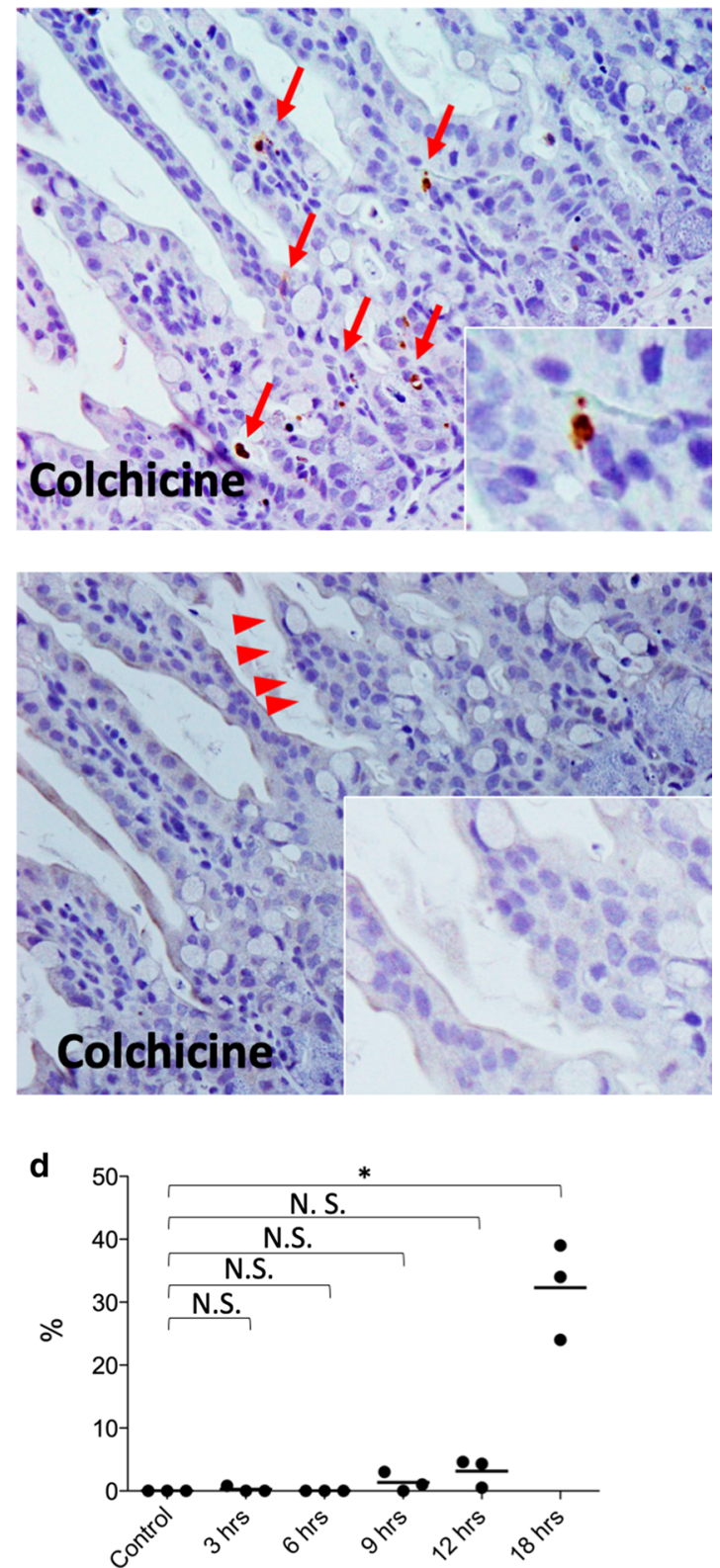

sequence of changes in the frequency of cleaved caspase-3-positive epithelial cells ( $n=3$ for each time point, $* P<0.05$, N.S.: no significance). $\mathbf{d}$ Time sequence of changes in the frequency of ZO-1-absent villi ( $n=3$ for each time point, $* P<0.05$, N.S.: no significance)

in the gastrointestinal tract. Furthermore, the serum levels of TNF- $\alpha$ were significantly increased $18 \mathrm{~h}$ after colchicine administration, resulting in endotoxemia. Serum endotoxin and TNF- $\alpha$ levels did not increase until $18 \mathrm{~h}$ after colchicine administration. These results suggest that colchicine inhibits cell growth and induces apoptosis in intestinal crypts, which results in intestinal renewal failure and deformation of tight junctions at the villi. Furthermore, endotoxin moves into the blood flow because 
Fig. 3 Time sequence of changes in serum endotoxin and tumor necrosis alpha (TNF)- $\alpha$ levels. a The levels of endotoxin in mice $(n=3$ for each time point, $* P<0.05$, N.S.: no significance). $\mathbf{b}$ The serum TNF- $\alpha$ levels in mice $(n=3$ for each time point, $* P<0.05$, N.S.: no significance). $\mathbf{c}$ The leaked from inside the intestines $(n=5, * P<0.05)$. The error bar indicates the SD levels of $\mathrm{H}^{3}$ radioactivity that
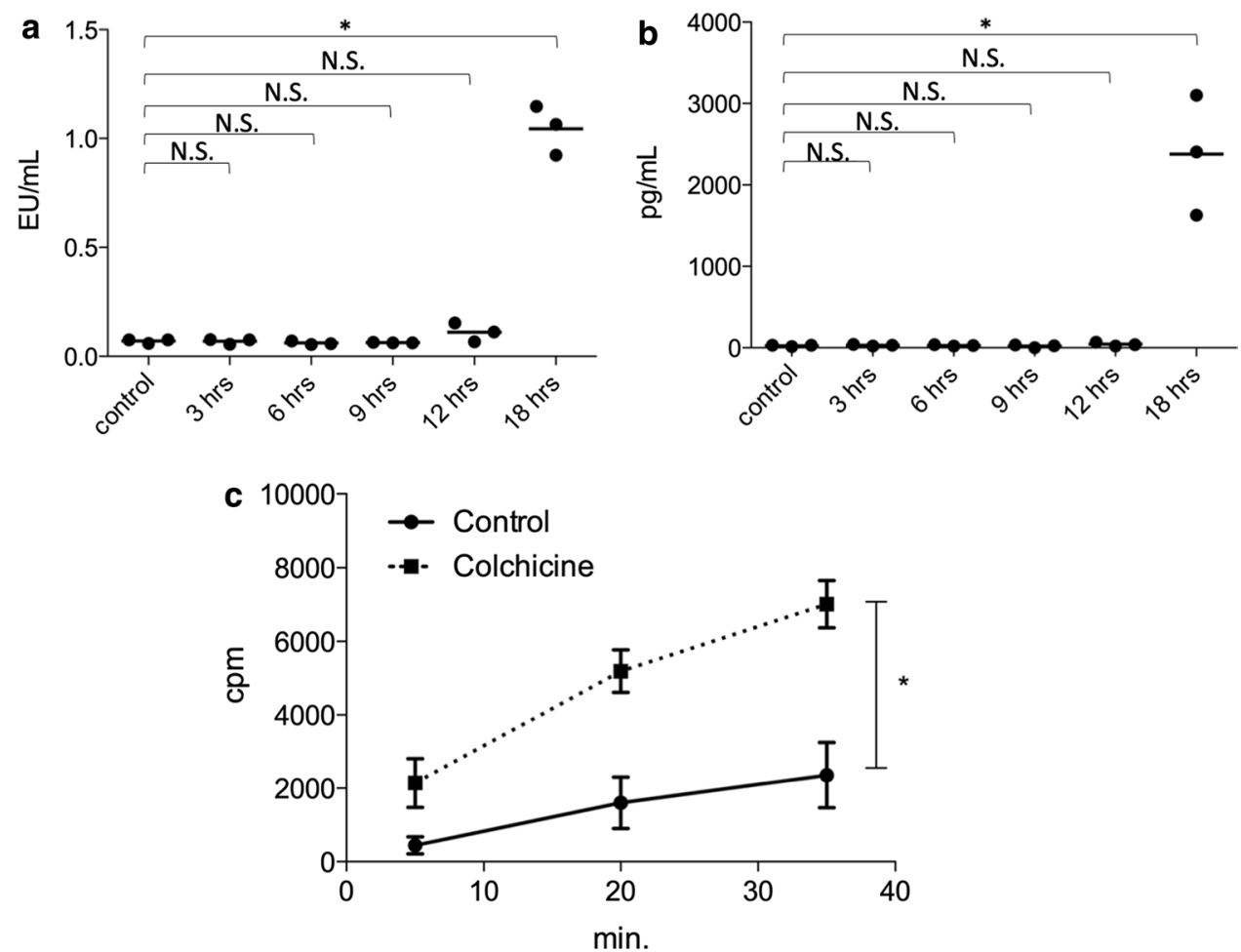

of reduced intestinal barrier function, causing massive cytokine production (Fig. 5).

It is reported that colchicine tightly binds to intracellular tubulin, and it is recycled by enterohepatic circulation [16]. Thus, colchicine itself is difficult to eliminate from the body. Several reports demonstrated that colchicine could be eliminated by the anti-colchicine antibody Fab fragment [17-19]. However, this antibody is not commercially available. Therefore, it is important to identify other therapeutic strategies. Our results indicated that inhibition of LPS-TLR4 signaling in the early phase of colchicine poisoning might prevent colchicine poisoning-induced death, even it did not directly reverse colchicine-induced endotoxemia or reduce intestinal permeability (Fig. 5). Severe damage in the gastrointestinal tract results in endotoxemia and triggers many other life-threatening symptoms such as dehydration, acidbase imbalance, and electrolyte abnormalities [1, 2]. However, LPS-TLR4 signaling inhibition completely prevented colchicine poisoning-induced death in mice, meaning that endotoxemia caused by colchicine ingestion was a critical cause of death in these animals. Therefore, it is important to prevent endotoxin bioactivity followed by gastrointestinal disorder in colchicine poisoning. These data are important for providing a therapeutic strategy for treating colchicine poisoning. For example, polymyxin B-immobilized fiber column hemoperfusion therapy might emergently prevent colchicine poisoning-induced death [20]. However, intracellular microtubules have a wide variety of roles in basic cellular function other than cell division, including protein assembly, endocytosis, exocytosis, cell shape maintenance, and motility. Hence, colchicine is toxic to all cell lines of the body. Thus, further studies are necessary to discover other mechanisms underlying colchicine poisoning.

In conclusion, we found that colchicine interferes with intestinal barrier function and induces endotoxemia in a murine model. Therefore, therapeutic intervention for endotoxemia might be beneficial in the treatment of acute colchicine poisoning. 
Fig. 4 The effect of endotoxin inhibition in colchicine-treated mice. a Survival curve of colchicine-poisoned mice that received TAK-242 $(n=10)$. b The levels of endotoxin in mice that received TAK-242 ( $n=10, * P<0.05$, N.S.: no significance). $\mathbf{c}$ The levels of $\mathrm{H}^{3}$ radioactivity that leaked from inside the intestines of mice that received TAK-242 $\left(n=5,{ }^{*} P<0.05\right)$. d The levels of serum TNF- $\alpha$ in mice that received TAK-242 $(n=10$, $* P<0.05)$
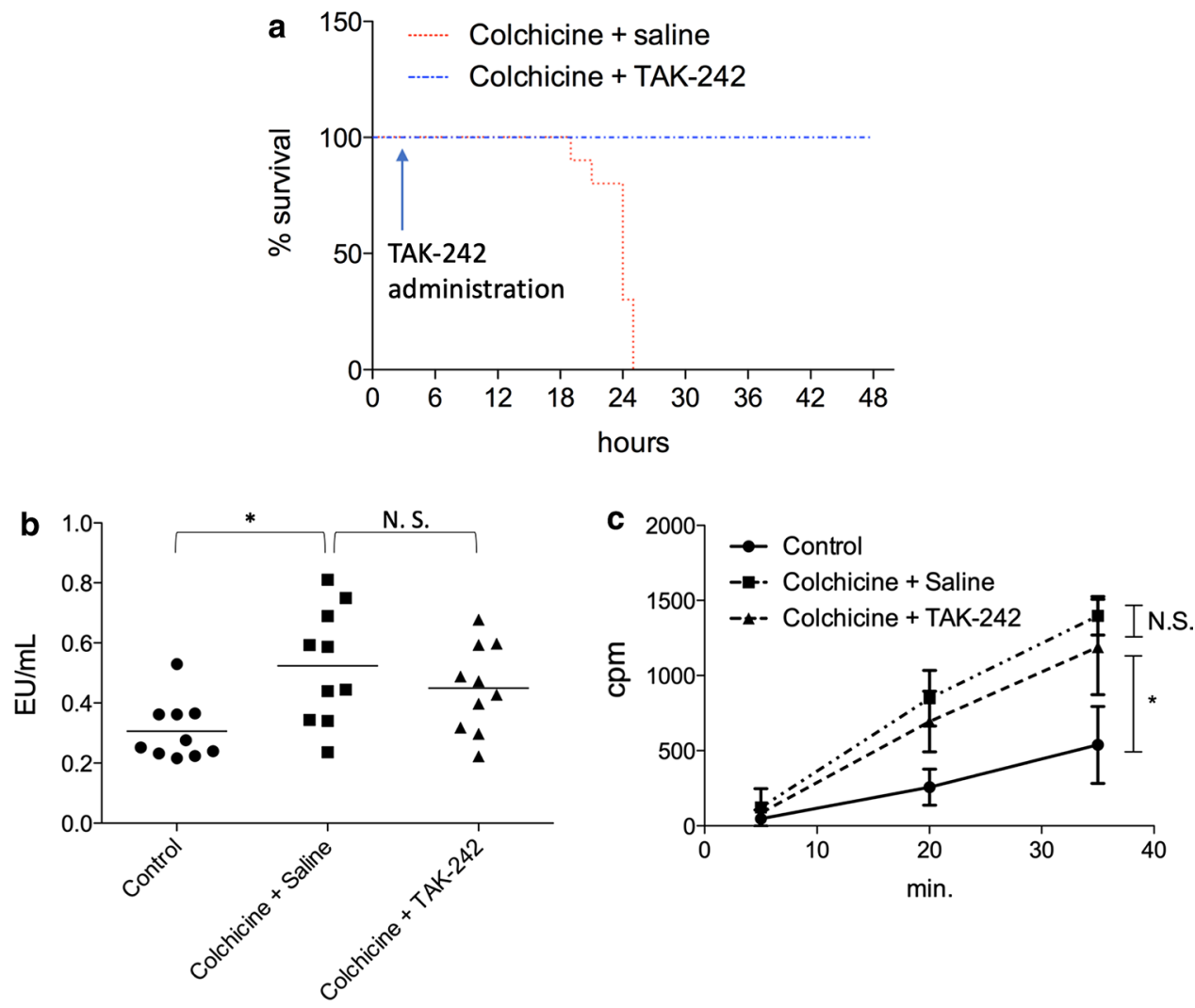

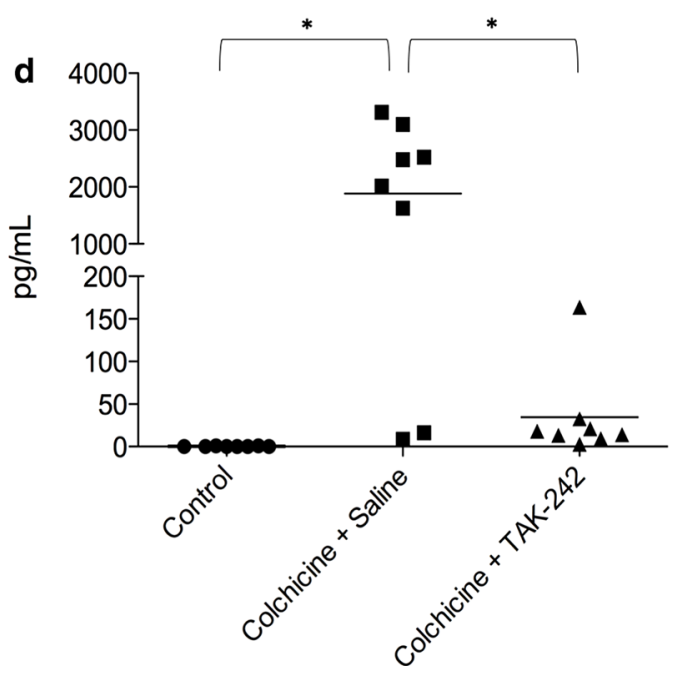


Fig. 5 The schema of colchicine-induced endotoxin shock

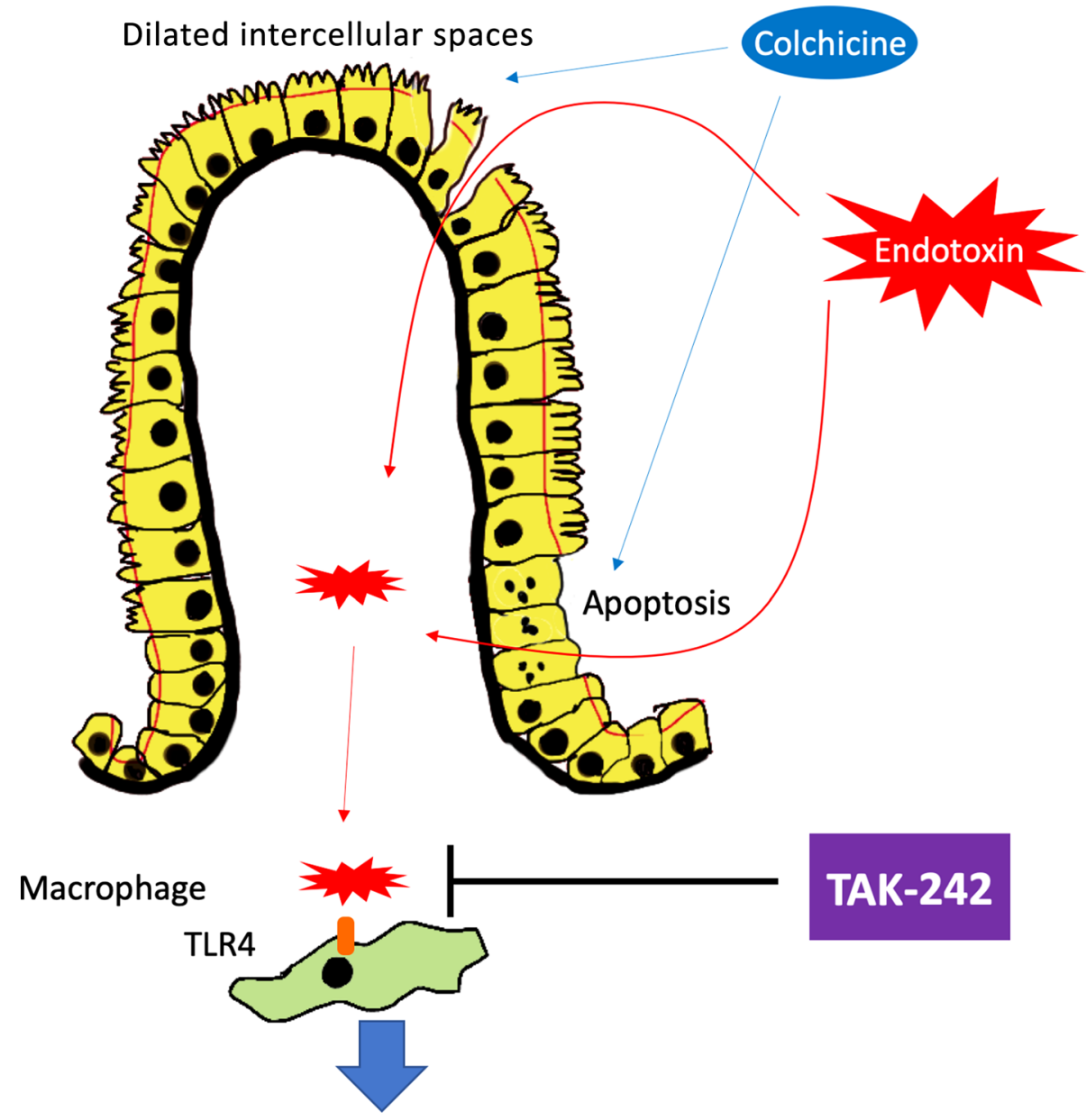

Cytokine secretion
Author's contribution $\mathrm{KH}$ and HT designed and performed all experimental procedures and wrote the manuscript. KH, SI, KOk, HK, and MA performed data analyses. HT, MF, and KOg supervised and reviewed this manuscript. HS and KS contributed to the acquisition of funding.

Funding This work was supported by JSPS KAKENHI grant number $17 \mathrm{H} 00693$ to $\mathrm{KH}$.

\section{Compliance with Ethical Standards}

Conflict of interest The authors have no conflicts of interest regarding the contents of this article.

Open Access This article is distributed under the terms of the Creative Commons Attribution-NonCommercial 4.0 International License (http://creativecommons.org/licenses/by-nc/4.0/), which permits any noncommercial use, distribution, and reproduction in any medium, provided you give appropriate credit to the original author(s) and the source, provide a link to the Creative Commons license, and indicate if changes were made.

\section{References}

1. Finkelstein Y, Aks SE, Hutson JR, et al. Colchicine poisoning: the dark side of an ancient drug. Clin Toxicol (Phila). 2010;48:407-414.

2. Terkeltaub RA. Colchicine update: 2008. Semin Arthritis Rheum. 2009;38:411-419.

3. Bhattacharyya B, Panda D, Gupta S, Banerjee M. Anti-mitotic activity of colchicine and the structural basis for its interaction with tubulin. Med Res Rev. 2008;28:155-183.

4. Nidorf SM, Eikelboom JW, Thompson PL. Colchicine for secondary prevention of cardiovascular disease. Curr Atheroscler Rep. 2014;16:391.

5. Deftereos S, Giannopoulos G, Papoutsidakis N, et al. Colchicine and the heart: pushing the envelope. J Am Coll Cardiol. 2013;62:1817-1825.

6. Amrollahi-Sharifabadi M, Seghatoleslami A, Amrollahi-Sharifabadi M, Bayani F, Mirjalili M. Fatal colchicine poisoning by accidental ingestion of Colchicum persicum: a case report. Am J Forensic Med Pathol. 2013;34:295-298.

7. Sannohe S, Makino Y, Kita T, Kuroda N, Shinozuka T. Colchicine poisoning resulting from accidental ingestion of meadow saffron (Colchicum autumnale). J Forensic Sci. 2002;47:1391-1396. 
8. Klintschar M, Beham-Schmidt C, Radner H, Henning G, Roll P. Colchicine poisoning by accidental ingestion of meadow saffron (Colchicum autumnale): pathological and medicolegal aspects. Forensic Sci Int. 1999;106:191-200.

9. Aghabiklooei A, Zamani N, Hassanian-Moghaddam H, Nasouhi $\mathrm{S}$, Mashayekhian M. Acute colchicine overdose: report of three cases. Reumatismo. 2014;65:307-311.

10. Hirayama I, Hiruma T, Ueda Y, Doi K, Morimura N. A critically ill patient after a colchicine overdose below the lethal dose: a case report. J Med Case Rep. 2018;12:191.

11. Delgado ME, Grabinger T, Brunner T. Cell death at the intestinal epithelial front line. FEBS J. 2016;283:2701-2719.

12. Pålsson-McDermott EM, O'Neill LA. Signal transduction by the lipopolysaccharide receptor, toll-like receptor-4. Immunology. 2004;113:153-162.

13. Yamada M, Kobayashi Y, Furuoka H, Matsui T. Comparison of enterotoxicity between autumn crocus (Colchicum autumnale L.) and colchicine in the guinea pig and mouse: enterotoxicity in the guinea pig differs from that in the mouse. $J$ Vet Med Sci. 2000;62:809-813.

14. Ueno N, Fujiya M, Segawa S, et al. Heat-killed body of Lactobacillus brevis SBC 8803 ameliorates intestinal injury in a murine model of colitis by enhancing the intestinal barrier function. Inflamm Bowel Dis. 2011;17:2235-2250.

15. Sha T, Sunamoto M, Kitazaki T, Sato J, Ii M, Iizawa Y. Therapeutic effects of TAK-242, a novel selective Toll-like receptor 4 signal transduction inhibitor, in mouse endotoxin shock model. Eur J Pharmacol. 2007;571:231-239.

16. Chen YJ, Huang SM, Liu CY, Yeh PH, Tsai TH. Hepatobiliary excretion and enterohepatic circulation of colchicine in rats. Int $J$ Pharm. 2008;350:230-239.

17. Peake PW, Pianta TJ, Succar L, Fernando M, Buckley NA, Endre $\mathrm{ZH}$. Fab fragments of ovine antibody to colchicine enhance its clearance in the rat. Clin Toxicol (Phila). 2015;53:427-432.

18. Baud FJ, Sabouraud A, Vicaut E, et al. Brief report: treatment of severe colchicine overdose with colchicine-specific Fab fragments. N Engl J Med. 1995;332:642-645.

19. Sabouraud A, Redureau M, Gires P, Martinet M, Scherrmann JM. Effect of colchicine-specific Fab fragments on the hepatic clearance of colchicine. Drug Metab Dispos. 1993;21:997-1002.

20. Shimizu T, Miyake T, Kitamura N, Tani M, Endo Y. Endotoxin adsorption: direct hemoperfusion with the polymyxin B-immobilized fiber column (PMX). Transfus Apher Sci. 2017;56:682-688.

Publisher's Note Springer Nature remains neutral with regard to jurisdictional claims in published maps and institutional affiliations. 